\title{
JUANA DE VEGA DESDE LA LITERATURA DEL YO
}

\author{
Ermitas PENAS VARELA \\ Universidad de Santiago de Compostela
}

\section{RESUMEN}

Este trabajo tiene por objeto el estudio de dos textos de Juana de Vega, autora de la segunda generación romántica, En honor de Mina (Memorias íntimas, 1805-1834) y Apuntes sobre la historia. Del tiempo que ocupé los destinos de Aya de S. M. y Camarera mayor de Palacio en el ámbito del género de la literatura del yo. Para ello se establecen relaciones entre ambos escritos con el espíritu egocéntrico de la filosofía y estética del Romanticismo, exaltadoras de la individualidad. Asimismo, se analizan las dos obras de la escritora coruñesa a la luz de la metodología propia del mencionado género literario, adscribiendo En honor de Mina a la autobiografía y Apuntes sobre la historia a las memorias.

Palabras clave: romanticismo, autora romántica, literatura del yo, individualismo egocéntrico, autobiografía, memorias.

\section{ABSTRACT}

This paper focuses on the study by Juana de Vega, second generation of romanticism author, of two pieces of her work in the area of literature of the self, En honor de Mina (Memorias intimas, 1805-1834) y Apuntes sobre la historia. Del tiempo que ocupé los destinos de Aya de S. M. y A. Camarera mayor de Palacio. For that purpose, links are established between both writings, with the egocentric spirit of philosophy and aesthetics of Romanticism. Likewise, both writings are analyzed from this literary genre, assigning En honor de Mina to autobiography, and Apuntes sobre la historia to memoirs. Key words: romanticism, romanticism author, literature of the self, egocentrical individualism, autobiography, memoirs. 
Sin duda, uno de los aspectos más característicos del Romanticismo es la exaltación de lo subjetivo frente al objetivismo racionalista. Y en consonancia con esto, el individualismo, de hondas raíces ilustradas, define al individuo como ser moral, independiente, autónomo y esencialmente social, lo que iniciará la concepción moderna tanto del hombre como de la sociedad (Dumond, 1977).

Este predominio del yo, desde la ladera intelectual o filosófica, no es en absoluto extraño que se plasme en la literaria. Surge, así, un tipo de escritos, con claros antecedentes en la literatura universal (Agustín de Hipona, Rousseau, Goethe...) y en la española (Teresa de Ávila, la picaresca, Torres Villarroel, Cadalso...) que se integra, homónimamente, en la llamada literatura del yo. Abarca ésta un amplio abanico de modalidades: autobiografía, memorias, diarios, epistolarios, poesía lírica con una clara impronta de su creador, autorretratos y la novela lírica, algunas de las cuales fueron cultivadas por nuestros autores y autoras románticos.

Entre ellas, las más conocidas son las escritas por Alcalá Galiano, Blanco White, Mesonero Romanos, G. Gómez de Avellaneda, Zorrilla u otros. Lo son mucho menos las de la coruñesa Juana de Vega (1805-1872), esposa del general Francisco Espoz y Mina, quien publicó no sólo las Memorias de éste (1851-1852)1, sino otras dos obras más, vinculadas a la literatura del yo: En honor de Mina (Memorias intimas, 1805-1834) y Apuntes para la historia. Del tiempo que ocupé los destinos de Aya de S. M. y A. y Camarera mayor de Palacio.

En ambos textos de la condesa de Mina, perteneciente a la segunda generación romántica como Larra y Espronceda, es palpable su estrecha relación, al ser páginas que nacen bajo un designio egocéntrico, con la filosofía y estética románticas que promueven la exaltación del yo. Es este poder del ego el que Friedrich Schlegel, en 1826, reconocía en la literatura moderna al mostrar ésta «la ávida sed de penetrar en lo individual» (Wellek, 1973: 19)². Y a través de esa indagación, los distintos autores desde Rousseau, Fichte o Herder cifrarán su interés por subrayar el sentimiento, lo irracional, la imaginación y fantasía, la sinceridad, el simbolismo, la desilusión o lo histórico (Wellek, 1983). Algunos de estos aspectos son fácilmente detectables en las dos obras de Juana de Vega.

Ella se convierte en tema y sujeto de En honor de Mina y en testigo de excepción de los sucesos narrados, vinculados a sí misma, en los Apuntes. En ambos, la rememoración del pasado que se trae al presente de la escritura es contemplada desde su particular perspectiva. A pesar de los títulos, confusos

1. Realmente ella misma las redactó a partir de los materiales proporcionados por su marido.

2. Reseña al Tasso de Wiffer (citada en Wellek). 
en la época y aún después, el texto nombrado en primer lugar es una autobiografía, subtitulado precisamente «Memorias íntimas», mientras que el segundo corresponde a unas memorias.

Estas dos contribuciones de Juana de Vega a la literatura o género del yo se publicaron conjuntamente, como obras póstumas, en 1910 por la editorial madrileña Imprenta de Hijos de M. G. Hernández. Reunidas ambas en un único volumen, llevan en la cubierta el título conjunto de Memorias de la Excma. Sra. Condesa de Espoz y Mina. En la portada consta que fueron revisadas por Manuel José Quintana y mandadas publicar por José Canalejas. Se acompañan, asimismo, de un prólogo de Juan Pérez de Guzmán y Gallego, académico de la Historia.

Explica en él los pasos que se dieron hasta que ambas obras fueron editadas por primera vez. Cuando Canalejas, presidente del Congreso, visita el archivo de la casa, a quien su autora los había legado, encuentra en él el manuscrito de los Apuntes para la historia. Persuadido de su importancia, se dispuso a sacarlos a la luz. Requirió, para ello, el concurso de los testamentarios de doña Juana y mediante este contacto se hizo con el manuscrito de En honor de Mina, aparte otros inéditos, desde documentos hasta cartas o el testamento, otorgado en 1869.

La donación de los Apuntes por la condesa al Congreso se había hecho con la condición de que no se publicasen hasta que hubiese pasado un tiempo prudencial. Pero llegaron a hacerse varias copias e incluso una se había vendido para hacerla pública. En vista de esto, el presidente decidió adelantarse. Pérez de Guzmán aclara que Canalejas

aceptando las ofertas que se le hicieron por los herederos de la Condesa, unió a esta obra otras Memorias que la misma señora tenía entre manos y dejó sin concluir a su muerte, y que con el título de En honor de Mina, retrocedían de nuevo a la época de sus últimas proscripciones, después de 1820 y hasta 1836, a pesar de tener ya publicados, desde 1851-52, los cinco volúmenes de las Memorias del célebre caudillo, su marido, en que ella trabajó tanto para ordenarlas, como si hubiesen sido también producción de su propio estudio e ingenio (1910: XIII).

Por tanto, la edición de 1810 contiene dos textos escritos en orden inverso a la cronología vital que reflejan. Primero redactó Los Apuntes, en cuyo final figura el lugar y fecha de su terminación: San Pedro de Nos, 29 de octubre de 1844. Abarcan un tiempo de dos años, el que estuvo en palacio, exactamente desde el 29 de julio de 1841 al 29 del mismo mes en 1843. Sin embargo, En honor de Mina. Memorias intimas, que quedó inconcluso a su muerte (1872), se escribió más tarde. Plasma la vida de Juana desde sus años infantiles hasta 
unas fechas situadas entre abril de 1833, en que su padre se queda paralítico, y el 15 de octubre de ese año, cuando la reina regente da la segunda amnistía.

No obstante, en la edición princeps en que los dos textos aparecen como autónomos, con numeración independiente, se sigue el orden de redacción: primero los Apuntes, cercanos a la experiencia vivida -en el subtítulo indica la condesa: «escritos inmediatamente después de mi renuncia»-y después En honor de Mina. Memorias intimas, mucho más alejadas. En el presente trabajo, sin embargo, invertiremos la secuencia cronológica puesto que la personalidad, las creencias, los más íntimos afanes de Juana de Vega, palpables en su autobiografía de la cual es protagonista, es lo que alienta las páginas históricas de sus memorias.

Es evidente que en la literatura del yo la intencionalidad con que se escribe el texto que el mismo escritor declara, incluso no llegando a coincidir con aquella, incide en una determinada selección de materiales o en su priorización, lo que al fin y al cabo constituye el contenido de la obra literaria. Así, en En honor de Mina viene precedido no sólo de un conjunto de referencias a su finalidad, sino a las motivaciones que llevan a su autora a la redacción de ese texto y, en suma, a declarar su naturaleza autobiográfica.

En primer lugar, Juana de Vega califica sus Memorias íntimas como «relación de los sucesos de mi vida» $(257)^{3}$. Confiesa que ha «vacilado mucho tiempo en la incertidumbre» (257) de si las escribiría. Desde su egocentrismo, no dudó en hacerlo porque lo deseaba, pero su propia existencia estuvo unida desde muy pronto a la de su marido, de quien ya se conocían sus Memorias, reflejo de su faceta de hombre público. Por tanto, fija la autora coruñesa un doble objetivo, en relación con ella misma y con el general:

después de largas meditaciones he venido a concluir que no debe ser materia de inclinación solamente, sino el cumplimiento de un deber, lo que me estimula a trazar estas líneas, que pueden dar a conocer en su vida privada a mi esposo don Francisco Espoz y Mina (257).

Pero el lector no debe engañarse porque, aunque esa duplicidad está estrechamente trabada, es a la personalidad de Juana, a su formación y a su manera de ser a quien se supedita todo el relato autobiográfico. De tal manera que éste se convierte -como íntención última- en «la más cumplida respuesta que puedo dar a los que han querido adornar con un colorido novelesco mi enlace» (258). Lo cual no admite porque sería contrario no sólo «al carácter y costumbres austeras de Mina» (258), sino a sí misma: «a la virtuosa educación que

3. Cito, y así en adelante, por la primera edición mencionada. 
tuve la inapreciable dicha de recibir, y he reputado siempre mi más precioso patrimonio» (258).

Además, J. A. Durán (2006) relaciona la decisión personal de redactar las Memorias intimas con una estratagema de la autora, consciente de su condición femenina y de las opiniones negativas que en la época suscitaban las escritoras:

Identificada con la idea (argucia) de contar su propia vida como si fuera siempre «En honor de Mina», las dudas que sembraban los prejuicios ambientales hacia las literatas comparecían de continuo (2006: 16).

Fue P. Lejeune (1994: 50) quien en 1975 caracterizó la autobiografía como narración retrospectiva que una persona real hace de su propia existencia, y en particular sobre la historia de su personalidad. La condesa de Mina, en este sentido, para que el lector comprenda el origen de la intimidad entre ella y su marido, y el cariño recíproco que siempre se tuvieron, se apresta a comenzar su tarea «hablando de mí misma» (16). La finalidad será marcadamente individual, aunque se intente corregir malentendidos y falsedades, y existan justificaciones casi siempre de tipo más personal que político (Caballé, 1881).

En En honor de Mina, como es obvio, el narrador se identifica con Juana de Vega, personaje clave y central del texto, que se focaliza desde un punto de vista del yo protagonista y está escrito en primera persona. Y será su propia subjetividad quien filtre necesariamente el contenido presentado al lector.

En la forja de la personalidad de la autora, esa que la hizo digna esposa de su admirado y querido Mina, tuvieron una influencia capital sus padres. Juan Antonio de Vega, hombre hecho a sí mismo en la emigración cubana, había regresado a La Coruña con abundante dinero como para convertirse en un próspero comerciante. Liberal, de carácter reflexivo y grave se había casado con María Josefa Martínez Losada, mujer inteligente y de recto juicio. Aficionados ambos a la lectura, la inclinaron a ella desde muy temprano y también propiciaron la participación en sus conversaciones, de las que «necesariamente -dice la condesa- había yo de sacar mucha utilidad en adelante» (260).

Juana destaca la esmerada educación que le procuraron sus progenitores. Varios maestros venían a darle clases a su casa y las lecciones eran presenciadas por doña María Josefa. Al lado de la típica educación para señoritas -música, baile, bordado, francés- se le impartía gramática, aritmética y dibujo. Todo su tiempo estaba ocupado por una metódica vida escolar, lo que la convierte en una especial niña solitaria, condición que no la entristece: «ni yo deseaba ni mis padres me habrían permitido lo que generalmente se permite a las niñas: reunirse con otras» (260). Fueron muy contadas las que había tratado 
en su infancia con la excepción de una, de la que conserva su amistad y cuya «educación no era tampoco común» (261) y su caracteres semejantes.

Dos aspectos, subrayados por la propia autora coruñesa, nos parecen relevantes a la hora de señalar el efecto beneficioso de sus padres y el ambiente familiar creado por ellos en una adolescente Juana, de doce o trece años: el contacto con las ideas liberales desde niña y su precoz vocación literaria.

Después de que Porlier fuese ajusticiado en La Coruña -3 de octubre de 1815- y sus compañeros encarcelados en el castillo de San Antón, tras su frustrado pronunciamiento contra el absolutismo de Fernando VII, las conversaciones sobre la mala suerte de los defensores de la libertad, las explicaciones de su padre y las lecturas graves son el origen de sus primeras tentativas literarias, en el campo del género epistolar. Pero el lector de En honor de Mina descubre, no sin asombro, que estas páginas no abordaban un tema propio de la ingenuidad o inocencia de una adolescente nacida en 1805, sino que trataban de política. Ese conjunto de elementos, mencionados más arriba, son asumidos por la condesa:

inflamaron mi imaginación en tanto grado que en esta época (entre 18171818) escribí varias cartas dirigidas a una amiga imaginaria, pintándole a mi manera la malograda tentativa de Porlier, su catástrofe y consecuencias, en las que sólo recuerdo que mostraba gran afán de que se comprendiese que los militares y no el pueblo habían hecho traición al malogrado general (266).

$\mathrm{Su}$ padre que lee y corrige el borrador se llena de legítimo orgullo al poder comprobar no sólo el talento de la niña, sino que ésta comulgaba plenamente con la causa de la libertad en la que había sido criada. La prudencia de la madre, que le había inculcado el sentido del verdadero honor y la obligación de no faltar a la verdad, le aconseja que no exprese sus ideas por escrito, lo que le lleva a guardar aquellas cuartillas. Posteriormente, se quemarían para «evitar compromisos» (267). También corrieron la misma suerte «otros pasatiempos de este género» (267) como un elogio a Sócrates, custodiado por su padre durante mucho tiempo.

Al liberalismo político, tan vivo en la familia, se unía la ideología liberal que se muestra en el tipo de educación recibida por Juana. Buena prueba de ese espíritu nada conservador son las obras ensayísticas que don Juan Antonio de Vega pone en manos de su hija -libros de viajes de Anacharsis y Antenor, el Teatro crítico de Feijoo...-, un tipo de literatura absolutamente vedada a las ignorantes jóvenes de su edad. Sobre su lectura se le hacían preguntas y se le daban explicaciones. Además, escribía a su padre sobre los pasajes de estas obras que más le habían llamado la atención para familiarizarse con el estilo epistolar. 
Pero no sólo, y gracias a sus progenitores, Juana alcanza una cultura digna de tenerse en cuenta, sino que aquellos libros «graves» (266) provocaron sus primeras incursiones en las letras: «no eran más- afirma- que la expresión del efecto que me producía la lectura» (266).

Ciertamente, $\mathrm{M}^{\mathrm{a}}$. Josefa y Juan Antonio no la trataban como una niña $\mathrm{y}$, fruto de su aliento liberal, confiaban en ella acrecentando su responsabilidad. No importaba que el motivo fuese suficientemente comprometido, como en los dos casos que cuenta, para conseguir asustarla o motivar su indiscreción. Uno de ellos tiene que ver con una misión que le encomienda su padre: llevar a un oficial fugado de la cárcel coruñesa y cobijado en una casa «los socorros que le iban a serle necesarios en una tierra extranjera» (268). El otro, con la entrada clandestina en la ciudad de Pedro de Olmos, compañero de Porlier, desde el exilio francés. Juana se enorgullece de sí misma: «y yo, que le conocía por la amistad con mis padres, supe este secreto» (268). De este modo, la muchacha no sólo se familiarizaba con el peligro que en tiempos de absolutismo acosaba a los defensores de la libertad, sino que templaba su carácter para hacer frente a situaciones arriesgadas. Cuando la autora cumple quince años tiene lugar el alzamiento de Riego que alumbraría el trienio liberal. Su ciudad natal, entonces, apoyó la revolución y el pueblo aclamó la Constitución de 1812 el 21 de febrero de 1820. Su padre fue nombrado vocal de la Junta de Galicia como hombre influyente y acaudalado. Al mismo tiempo, Espoz y Mina, tras penetrar en Navarra y proclamar el código doceañista en Santiesteban a comienzos de marzo, era nombrado capitán general de Navarra y Cataluña. A finales de año pide el traslado a Galicia, lo que consigue en 1821 como comandante general, precisamente cuando don Juan Antonio marcha a Madrid.

No puede pasarse por alto en estas Memorias intimas de Juana de Vega, el gran impacto que el patriota de la Guerra de la Independencia le produce cuando desde el balcón de su domicilio presencia el recibimiento que la ciudad le tributa:

Nunca olvidaré la impresión primera que en mí hizo la vista de Mina; de aquel Mina de quien tanto había oído hablar y cuyas proezas, referidas por mis padres con gran entusiasmo, se habían grabado en mi memoria al lado de las que había leído de los héroes en mis libros favoritos (270).

Evidentemente, la condesa llega a estimarlo antes de verlo por primera vez. Incluso, el coronel Peón, en su visita a la familia, había añadido al reconocido valor y patriotismo del general otras cualidades como la honradez, el desprendimiento o la generosidad que evitaban que fuese un hombre rico. Todo ello - confiesa la joven de dieciséis años- había «excitado mi admiración, su 
pobreza y su virtud realzaron su mérito para mí de una manera extraordinaria, pasando a ser objeto de veneración y respeto» (271).

Pero «la impresión primera» que Mina causó en Juana, predispuesta muy positivamente hacia él como hemos visto, es su aspecto físico. Le sorprendió y desde luego le gustó aquel hombre que había cumplido los treinta y siete: «conservaba toda la fuerza y gallardía de la juventud, su semblante era muy agradable y varonil, su mirada penetrante y expresiva» (270). Sin duda, lucía bien en su caballo mientras el pueblo lo saludaba y él le correspondía «con urbanidad y modesto encogimiento» (270).

Sin embargo, es curioso comprobar que esa imagen de Mina percibida por la escritora gallega encaja con la idealizada que ella había fantaseado: «su figura vino a dar vida, realzándolo, el cuadro que mi imaginación se había pintado» (270). Es decir, todas las cualidades del general que Juana había conocido de oídas la habían conducido a prefabricar en su mente un ser semejante a un héroe literario, y aun romántico. No podía, por tanto, ser feo ni decrépito.

Faltaba, no obstante, el trato personal y privado. Éste se produjo cuando el general a los pocos días fue recibido en su casa por la joven y su madre, estando ausente el padre. La conversación, los modales, el carácter reservado, la contención en los juicios que emitía en nada alteraron «la opinión anterior» (271) que sobre él tenía la muchacha.

A tenor de lo que venimos analizando, no hay duda de que la condesa encuentra, siendo muy joven, a un ser, según ella misma lo pinta, perfecto. Además, en seguida se atrajo las simpatías de los gallegos por «la rectitud de sus disposiciones y la cordialidad de su trato» (272). Hombre afectuoso, modesto, constante y sencillo, vivía con decoro pero sin ostentación, no tenía soldados a su servicio particular, vestía siempre de paisano, excepto en las ocasiones que la etiqueta exigía el uniforme, y obraba con prudencia persiguiendo el bien público.

Juana había tenido varios pretendientes y la cordialidad que existía con su madre permitía que ésta le dijese que cuando hubiese elegido se lo comunicase. Lo que prueba que, dado el ambiente liberal que reinaba en la familia, sería impensable un matrimonio impuesto. Todo lo contrario: sus progenitores simplemente le aconsejaban que fuese persona virtuosa y que la elección recayese en quien su corazón le dictara. No les preocupaba la solvencia económica del futuro marido.

Aunque madre e hija no acudían a tertulias y ésta no las echaba de menos gracias a su «afición a la lectura» (275), diariamente recibían a un conjunto de amigos. Mina las visitaba pero no con frecuencia, de tal manera que las relaciones con ellas «no se habían estrechado» (275). Cuando sucedía esto, 
siempre estaba doña María Josefa presente y si le dirigía la palabra a la joven era en conversación general. Por tanto, Juana nunca sospechó que el general se interesase por ella. Su sorpresa fue grande cuando, estando sola en la casa, éste le envió como emisario a su amigo de confianza Andrés Rojo, que también lo era de sus padres desde antiguo. Colaborador de Porlier y huido a Londres, que había conocido a Mina en el exilio parisino, le comunica de su parte que, sabiendo que sus progenitores le daban libertad para elegir marido, y si no estaba comprometida, lo aceptase como esposo.

Turbada ante semejante proposición, la muchacha de dieciséis años reacciona de manera insólita teniendo en cuenta su atracción y admiración hacia su héroe intachable. El molde literario o el comportamiento sentimental y soñador ahora no actúan. Juana no sólo, mostrando la confianza recíproca con sus padres, rehúsa por si esto les desagradase, sino que, muy juiciosamente, se reivindica como persona. El yo femenino, el individualismo romántico ejerciendo la liberalidad, aunque agradeciendo la propuesta, le lleva a no aceptarla porque -dice- Mina «no me conocía lo suficiente para juzgar de mi carácter» (277).

Enterada doña María Josefa por su hija de lo que había sucedido, también se quedó sorprendida y «su penetración» (279) le hizo descubrir que, si ella y su padre se oponían al enlace con el general, esto sería para la joven «un sacrificio» (279), ya que se había enamorado de él. Tanto era así que la condesa se admiraba de que ante el proyecto no le arredrase la inevitable separación de su familia.

Rojo regresó al día siguiente de este acontecimiento a la casa de los Vega para hablar con la madre y decirle que Mina, ya sabedor de la opinión de Juana, le escribiría a su padre. Cuando éste conoce por la misiva del general y por la carta enviada por su esposa a Madrid lo que estaba ocurriendo, da su aprobación dando libertad absoluta a su hija, que debe decidir por sí misma. Y así lo hizo: ante su madre y Rojo da palabra de matrimonio a Francisco Espoz. La convicción de su respuesta - «Creo que seremos muy felices, señorita» (280), la convenció de que era premonitoria pues la escritora lo ratifica -«Lo fuimos» (280)-, a pesar de haber sufrido «todo linaje de contrariedades y sinsabores» (39).

El aspecto halagüeño de las relaciones personales que, como es natural, ahora se intensifican más, no se correspondían con el de las cosas públicas pues comenzaban a torcerse hacia el absolutismo. Mina, temiendo que por su credo liberal pudiese ser perseguido si aquel volvía a triunfar, expuso a su joven prometida la posibilidad de que acabasen emigrados en un país extranjero. Le pide que reflexione sobre esto -la lejanía de sus padres y de la patria, 
también las incomodidades propias de la situación- y muy conmovido le dice que piensa en dejarla libre. Juana, aun siendo una adolescente, muestra otra vez su valentía y el amor hacia el hombre que había elegido para compartirlo todo, lo bueno y lo malo:

Yo le escuché llena de admiración, y comprendiendo, a pesar de mi juventud, toda la grandeza de aquel paso, ratifiquele la promesa de ser suya, con mayor decisión aún desde que me hacía entrever en lontananza la desgracia (282).

La autora coruñesa, que recrea en la escritura esa circunstancia, la considera desde su presente cargado de experiencias, como «un momento solemne» (282). Y no se equivocaba: ahora Mina ya la conocía y podía formar opinión sobre su carácter, también comprendería que estaba dispuesta a asumir su complicada existencia, y además una ilimitada y recíproca confianza se asentaba entre ellos.

No mucho después el general es destituido de su cargo y se le ordena dirigirse a Sigüenza, aunque el pueblo de La Coruña lo apoye. A pesar de ello, la situación se complica y, finalmente, la boda se celebra por poderes, al estar Mina oculto, en la casa de la novia, situada en la calle Real, el 24 de diciembre de ese año de 1821, excepcional en la vida de Juana de Vega.

Si nos hemos detenido en el proceso personal y privado que condujo al matrimonio entre la autora y el general, es porque ella lo hace en su autobiografía. Y esto no resulta casual, todo lo contrario. Planteaba en el comienzo de ésta que el relato servía para desmentir el aire «novelesco» de su enlace que algunos quisieron darle. En principio, podría aceptarse que lo fuera la ceremonia, dadas las circunstancias que la rodearon, pero Juana no se refiere a esto sino a la unión entre un hombre maduro y famoso con una muchacha mucho más joven, sin experiencia, y de familia acomodada.

La autora quiere con su narración demostrar varias cosas. En primer lugar, la sinceridad de sus sentimientos recíprocos - «era mi cariño de esos que no conocen obstáculos»; «me amaba apasionadamente»-que es lo que la lleva a elegir sin la imposición paterna. También que la admiración hacia Mina se une al agrado que su persona le produce, razones más que suficientes para casarse con él. Pero, sobre todo, lo que Juana quiere reclamar como propio es que la educación liberal y esmerada que le proporcionaron sus padres ha forjado una personalidad muy completa: un carácter decidido, valiente, respetuoso y cabal. En suma, la escritora coruñesa, desde ese presente en el que cuenta, tiene una clara voluntad de mostrar que ella, a pesar de sus pocos años, era suficiente madura para unirse al general y que, por tanto, ese matrimonio no tenía nada de las exaltaciones soñadoras tan propias de las novelas. 
Cuando Mina cumplía con su destino en León, ciudad nada liberal a la que finalmente le habían enviado, es repuesto en su cargo, después de los sucesos del 7 de julio de 1822 que llevan a los liberales progresistas al poder. Es, entonces, destinado a Cataluña, y Juana, que no puede acompañarle, se queda en Madrid con su padre. Comienza, así, con la primera separación de la pareja, su «agitada vida» (317). Pero aquella no será la última, de lo que la joven esposa culpa a «la imperiosa ley del destino» (300). Además, la condesa, que pronto ha descubierto el valor que ella tiene para su marido, confiesa que esos alejamientos constituyeron «siempre el mayor sacrificio de Mina para su patria» (300).

Apela aquí la escritora gallega a varios elementos que se integran con pleno derecho en la tópica del Romanticismo: el hado, el amor y el deber patriótico. Pero, además, no hay duda que los quince años de la existencia de Juana de Vega, ligados al general y relatados en su inconclusa autobiografía, pueden ser calificados, sin exageración, de románticos. No es mi intención, desde luego, detenerme en ellos, pero sí destacar que, como en toda narración autodiegética y focalizada por un yo protagonista (Genette, 1972), las Memorias intimas en los que se plasman son un acto de búsqueda de la identidad (Alfaro Amieiro, 1993) de la propia escritora. Y no sólo eso, en tanto la autobiografía de Juana de Vega se funda en la introspección o autorreflexión al llevar al papel sus recuerdos, es también un intento de transformación.

Cuando Hegel en sus conferencias o lecciones sobre estética, pronunciadas en 1818, muestra la interrelación implícita entre la mente, el poder creador y la divinidad, llega a expresar en sus formulaciones un punto de vista filosófico a partir del cual comenzó a evolucionar el interés romántico hacia la subjetividad y la vida íntima o interior. Coherentemente, en relación con ello, también el desarrollo de un hipotético conocimiento de uno mismo.

Así, la escritora coruñesa, de seguir la noción hegeliana de la «actividad práctica» (1990) como escritura, se «reduplica» a sí misma al rememorar su propia experiencia del pasado. Y es que la conciencia es algo que se obtiene y actualiza por medio de ese texto autobiográfico, el cual se produce en y por obra del lenguaje literario (Jay, 1993). Así, éste no sólo transforma ese tiempo pretérito, sino que el yo protagonista, narrador y sujeto de aquel texto también sufre esta transformación (Jay, 1993: 40).

Es más, la construcción de una identidad que se autotransforma literariamente tiene mucho que ver con recuperar un pasado que, al analizarse en la escritura, contiene un claro poder de liberación espiritual. Y, precisamente, esa recuperación de lo que ya fue y la transformación textual del yo es, 
para M. H. Abrams (1970), el fundamento del modelo de las autobiografías románticas.

De este modo, Juana de Vega en En honor de Mina. Memorias íntimas no va a dejar de narrarse construyéndose, pero lo hará como si de una auténtica heroína se tratase. No como una heroína romántica en un sentido literario, ya que su personalidad y carácter, del que ya hemos hablado, no se asemejan al de las protagonistas de tantos dramas y novelas, con excepción del gran amor hacia su marido y su temor al destino. Pero sí, en una acepción coloquial del término, por las aventuras, peligros o trabajos que padece. Y si se quiere, como figura central del romance con que nos pinta su vida con Mina.

Desde que éste la deja en Madrid con su padre, sufre las intrigas que planean contra su esposo a causa de la envidia, y ciertos engaños. También, se acude al soborno político para que mediante una carta convenza al general a pasarse a los que querían reformar el código doceañista para rebajar las libertades. Juana lo considera traición, además de agravio y ofensa para sí misma y su marido. Y así exclama: «iAbandonar Mina la causa del pueblo, al que se gloriaba de pertenecer, y buscarme a mí para instrumento de semejante plan!» (306). Disculpa a quien le había traído el mensaje por no conocer su don más preciado: la educación que había recibido, de la que siempre se muestra orgullosa, y su ideario liberal. La negativa que dio en esta ocasión y el control sobre otras situaciones difíciles evidencian su perspicacia y madurez, que le llevan, también, a constatar las fracciones del partido en que militaba. De todo ello, sin embargo, no comunica nada a su marido para no preocuparlo.

Cuando a principios de octubre de 1822 va a ver a su madre a La Coruña, mientras la ciudad celebraba los éxitos bélicos de Mina, las cuestiones políticas, enturbiadas por la amenaza absolutista, no dejan de afectarle. Se intercepta el correo y deja de tener noticias del general. Las cosas empeoran diariamente, lo que aumentaba -confiesa la autora gallega- «el desasosiego en que vivía» (313), hasta tal punto que al sitiar los franceses su patria chica, ella y su padre emprenden un complejísimo viaje a Gibraltar para esperar allí con más tranquilidad el desenlace de todo aquello.

La partida es afrontada por Juana con ánimo contrito, pues su «situación era muy crítica «(317) ya que dejaba a su madre en una ciudad sitiada, emprendía una singladura incierta, ignoraba si su «mala estrella» (317) la haría caer en poder del enemigo y hacía dos meses que no recibía cartas de su esposo. No es de extrañar, pues, que aquellos momentos fueran de «abrumadora angustia» (317). Pero, además, ese viaje nunca llegó a su destino. Después de peligros de todo tipo, llegaron a Lisboa en un momento inoportuno al apoderarse del trono Miguel de Braganza con un golpe de estado absolutista. 
La estancia allí es tan complicada que, desconociendo lo que ocurría en La Coruña y le sucedía a Mina, navegan hacia el Norte y se instalan en Caminha. Pero aquí la policía portuguesa vigilaba férreamente a los extranjeros y, tras nuevas aventuras, regresan a España. En Tuy se enteran de la abolición de las libertades, que en 1823 iniciaba la ominosa década. En la finca de San Pedro de Nos les esperaba doña María Josefa.

El epílogo de este romántico viaje lo pone la honrosa capitulación del general, que Juana vive con ansiedad, imaginando el empeoramiento de su salud, y su marcha al exilio inglés por tiempo indefinido.

Una vez que sabe que Mina se encuentra en la capital británica, cuyos periódicos le daban la bienvenida al tiempo que recibía visitas oficiales, comienza los preparativos para reunirse con él. No sabe la condesa, sin embargo, que su marido está cada vez peor de la pierna herida «en la memorable retirada de Naria» (348), al agravarse en el penoso viaje marítimo a Plymouth.

Juana sale de La Coruña con su padre que por motivos políticos tampoco podía permanecer en España. Relata el enorme dolor que sintió al despedirse de su madre, forzada a quedarse por su precaria salud y la necesidad de velar por los intereses familiares. También lamenta las veces que se arrepintió de no habérsela llevado con ellos pues nunca más la verían, ya que fallecería en 1829.

Al fin, después de dos años, el matrimonio se reencuentra. Dos eternos años, como la escritora dice, por «tantas penas, tantas incertidumbres y esperanzas frustradas» (364). La alegría connatural al suceso se ve enturbiada por la transformación física y anímica, producto de la enfermedad y los padecimientos morales, que sufre Mina: una nueva preocupación para su esposa. Ésta se había separado de él en Madrid «dejándolo en el completo goce de su robustez y agilidad, con la animación y la alegría en su noble semblante, y ahora le hallaba triste, decaído, con la cabeza encanecida» (364) y cojo, auxiliado por una pequeña muleta.

Su vida en Londres será modesta y el general mantendrá allí relaciones con Madrid a través de determinados correos y personas a quien se le encargaba alguna comisión. El gran número de emigrados que había en la ciudad, Juana los clasifica en dos tipos:

muchos comprometidos, otros que se consideraban tales por la brutal reacción que dominaba en España, y algunos también aventureros, advenedizos, que a favor de la política iban a buscar fortuna (366).

Estos últimos le causaron graves disgustos al acusar a su marido de que, desde su opulencia, no ayudaba a los exiliados, y también al mostrarle su ingratitud. 
A esta clase pertenecían no pocos de los numerosos agentes que el gobierno español pagaba para que espiasen a los liberales.

La actividad del general fue incesante durante todo su exilio desde que «al comenzar el año 1824» (372) empezara sus «trabajos patrióticos» (372). La finalidad única de éstos era el restablecimiento de la libertad en España: «liberar a la nación del yugo tiránico que la oprimía y conseguir que fuese árbitra de sus futuros destinos» (372). Para ello, había establecido toda una red de enlaces y corresponsales con diversos puntos de la península, Gibraltar y Portugal, y una Junta formada por varios ilustres emigrados que analizaba y contestaba a las noticias recibidas. Así, pues, una perfecta organización. Sin embargo, la necesaria reserva con que operaba propició celos de algunos y calumnias contra Mina, quien evitaba continuamente conflictos con los leales a base de aconsejar prudencia. Otros, por el secreto con que todo se llevaba, criticaban la inoperancia del general y difundían que se había pasado a la Santa Alianza.

El recuerdo de otros incidentes hace comprender al lector las continuas dificultades por las que Juana y su marido habían pasado. Aunque Mina ya se había recuperado de la pierna, una noche muy fría en que regresa a pie a su casa, después de haber sido invitado a cenar, se queda totalmente inmovilizado, lo que en principio se atribuyó a un envenenamiento; una doncella divulgaba noticias de la intimidad familiar; un secretario calumnia a Juana asumiendo la consigna de los detractores de Espoz de que no actuaba a favor de la patria porque ella se lo recomendaba. Incluso, en el invierno de 1825 tienen que trasladarse a Plymouth para que Mina siguiese un tratamiento especial en un clima más benigno, pero su dolencia artrítica se agravó y sufría horribles dolores en las extremidades y en las uñas.

No explica Juana la causa de la marcha a Francia, posterior a los contactos de su marido con el futuro rey de Francia, Luis Felipe I, duque de Orleáns, al interrumpir su relato con puntos suspensivos. Se deduce, sin embargo, que tiene relación con las esperanzas dadas por el monarca galo, considerado liberal, a la pretensión de los emigrados de producir un cambio de dinastía en España, para lo que, incluso, había insinuado que el candidato fuese su hijo mayor. Se supone que desde Francia estas negociaciones serían más fructíferas y el plan de ejecución más factible por la cercanía de España.

Sin embargo, a tenor de los hechos, juzga Juana de «maquiavélica conducta» (383) el comportamiento de Luis Felipe, quien había dado al traste con el pronunciamiento -18 de octubre de 1830- de su esposo, un plan que en el agosto anterior contaba con el apoyo del mariscal Gerard, ministro de la guerra, fruto de seis años de trabajo, encaminado a dar la libertad constitucional 
a nuestro país. Este es un dato que Mina no hace público en su momento porque había dado su palabra de guardar tan importante secreto, pero sí su mujer, ajena a tal compromiso, sabiendo que favorecería muy poco la reputación del monarca. La condesa, desde su individualismo, se muestra como garante de la verdad: «me incumbe publicar la causa [...] y poniendo en su verdadero punto de vista los sucesos, dejar que sean juzgados por el lector y recaiga su imparcial fallo sobre ellos» (384).

En cuanto a la interrupción del relato, Durán (2006: 124) opina que se debe a que son momentos ya narrados en las Memorias de Mina.

El encuentro del matrimonio tuvo lugar en Burdeos, donde ya estaba la condesa, el 2 de diciembre de 1830, después de que el gobierno francés obligase al general a abandonar Bayona. A pesar de que su dolencia se había agravado y del desengaño sufrido, Mina no decae. Establece contactos dentro y fuera de España, lo cual era operación de alto riesgo pues la ley de octubre de 1830 condenaba a muerte a los que tuviesen correspondencia con los emigrados. En esa época también la policía había descubierto en Madrid a algunas personas que se hallaban en comunicación directa con él, las cuales fueron encarceladas e, incluso, ajusticiadas. Por tanto, varias circunstancias contribuían a que Espoz llevase todo lo relativo a su trabajo político con suma reserva, ya que toda precaución era poca.

Con gran peligro, y usando un pasaporte falso, entró en París, con el fin de hablar con el emperador de Portugal que había abdicado y deseaba que le sucediese su hija, arrojando del trono a su hermano el infante don Miguel que lo había usurpado. Estas conversaciones tenían sentido ya que Mina y los exilados portugueses siempre habían pensado en una operación conjunta para proclamar la libertad en toda la península. En la capital, aunque era vigilado por la policía, estrecha relaciones con Mendizábal, principal agente de aquella arriesgada empresa, que también había tomado parte activa en la malograda tentativa de Mina en la frontera francoespañola, en octubre de 1830.

Juana permanecía en estos tiempos en «una continua alarma» (388) al repetirse sucesos peligrosos como el protagonizado por un policía secreto que había pretendido engañar a su esposo o el que intentaran envenenarlo. Transcurrido el año 1831, en el siguiente se intensifican los preparativos para la expedición del emperador don Pedro a Portugal. La esperanza en el éxito de su plan alentaba a los liberales españoles y a los emigrados ya que confiaban en las consecuencias positivas contra el absolutismo fernandino. Era mayo de 1832 y en aquellos días, Mina recibía comunicaciones andaluzas desde Gibraltar de que harían un nuevo pronunciamiento y necesitaban de su presencia. Decide ir: su reputación se lo exige. Hace partícipe de la noticia a su 
mujer, por la confianza que siempre había imperado entre ellos e, incluso, le enseña las cartas que habían mediado entre él y los liberales andaluces. Una vez más, Juan tiene que aceptar, aunque, reciente todavía el fiasco del pronunciamiento de Torrijos, tema una catástrofe parecida. Deseaba oponerse pero como confiesa en relación a su marido: «Ciertamente que no lo habría amado con el extremado cariño con que lo amé si su honor no hubiera sido para mí preferible a todo» (394). No obstante, cae enferma por los «amargos días» (394) que había pasado.

Llegamos así a uno de los puntos culminantes en la trayectoria vital de Juana de Vega al lado de su marido: a sus veintisiete años asume, por la ausencia de Mina, su secretaría política, aunque desde 1830 ya hacía de escribiente. Ella, discreta y humilde no quería pero acepta, creyendo que sólo sería por un mes. Más que nunca el general hace depositaria a su esposa no sólo de su confianza, sino que le confiere una labor de enorme y peligrosa responsabilidad. Las cualidades de Juana, la educación recibida, su personalidad nada común, a cuya construcción asiste el lector, posibilitan que éste no se sorprenda por su nueva tarea.

Lo primero que hace, para burlar el peligro, cuando todo estaba ya preparado para la salida hacia Gibraltar, es escribir sueltos, que una persona de confianza llevaba a los periódicos, en los que decía que el general se dirigía a la frontera con algún objetivo político. Los artículos fueron apareciendo con el intervalo necesario para que el supuesto viajero recorriera la línea Bayona, Pau, Tolosa y Marsella, produciendo el efecto de despistar a la policía. También, los esposos tomaron todo tipo de precauciones, incluso acudiendo a lugares muy concurridos de París, el primero de junio. A las once se dirigieron a la fonda donde vivían, Mina se disfraza y en una silla de postas es conducido a Boulogne. Juana se refiere a su nerviosismo y afirma que aceptar la marcha de su esposo fue uno de los mayores sacrificios que hizo por su patria: otra vez el honor del general le exigía sufrir nuevos peligros.

De nuevo, la vida romántica de la escritora gallega se asemeja al romance más tópico y, sobre todo, cuando al regresar a la fonda, cree padecer el cólera, que en esos momentos hacía estragos en París. Estaba sola y si pedía ayuda, se descubriría la fuga de su marido, lo que le hace exclamar contando con la comprensión del destinatario de su autobiografía: «iFigúrese el lector la terrible situación en la que me encontré!» (398).

Cuando la ausencia de Mina se hace evidente en el entierro del general Lamarque -4 de junio- las dificultades se incrementan. No cesan las pesquisas y ardides de la policía para dar con el paradero de Espoz. Además, para empeorar las cosas, los emigrados se creían desairados y se quejaban por tanto 
misterio. Al fin, tras «muchos días en la más cruel incertidumbre» (402), sabe que su marido había pasado por Londres y de su llegada a Gibraltar el día veintitrés, tras una travesía complicada. Ni en la ciudad del peñón ni en el viaje a Oporto las cosas mejoraron, al tiempo que la enfermedad de Mina se agravaba. Se entera éste por los corresponsales que el alzamiento liberal se había frustrado y que la reina, por la enfermedad de Fernando VII, había dado un primer decreto de amnistía el 14 de septiembre de ese año de 1832. Así las cosas, el general regresa a Londres donde llega con muy mala salud y decaído por los que con tanto descaro habían faltado a sus promesas.

Comienza, entonces, la vuelta de los emigrados. El padre de Juana, ya viudo, es convencido, pues podía acogerse al mencionado decreto de amnistía, de que debía regresar para así pedir el reintegro de sus bienes, incautados por el absolutismo. Pero don Juan Antonio, víctima del exilio por haber pertenecido a la Junta soberana que en febrero de 1820 se había instalado en La Coruña, tiene un accidente en abril de 1833 cuando la fecha del viaje ya estaba fijada. Salvó la vida pero quedó paralítico por lo que aquel no fue posible.

Las Memorias intimas de Juana de Vega, que nunca finalizó, terminan con la negativa de Mina a regresar a España, aunque se le había pedido reiteradamente que apoyase la causa de la futura Isabel II ante las pretensiones del infante don Carlos. Fernando VII moriría el 29 de septiembre de 1833 y el 15 de octubre $\mathrm{M}^{a}$. Cristina, en calidad de regente, daría otra amnistía con lo que el marido de Juana volvió a su país, reconociéndosele su graduación militar.

Como toda autobiografía, la de la condesa bascula entre la ficción y la realidad, entre la fábula mentirosa y la narración veraz, autentica paradoja para D. Villanueva (1993). Es decir, la escritora coruñesa a la vez que se esfuerza para que el lector tome como cierto lo que cuenta, no hay duda de que también selecciona, oculta o manipula ciertos datos. Algunos son muy llamativos como el utilizar previsoramente sólo las iniciales de los nombres de ciertas personalidades, no mencionar la relación de Mina con la masonería o edulcorar la crueldad que en las acciones guerreras se le atribuía como mandar fusilar, años más tarde, a la madre del militar carlista Ramón Cabrera. Por otro lado, silencia algo que señala Durán (2006: 133): el desacuerdo entre el general y los Vega en cuanto a los pronunciamientos liberales. La familia de Juana desconfiaba de ellos, desde el protagonizado por Porlier, por las divisiones existentes entre los militares implicados. También, que el matrimonio no estaba siempre de acuerdo, más a partir de 1830 y, sobre todo, en el último tramo de la vida de Espoz, entre 1834-1936, tras su regreso a España (Durán, 2006: 157). Asimismo, la autora se explaya muy poco en los recuerdos de su niñez, centrados exclusivamente en lo concerniente a su educación y carentes de lo 
propio de la edad infantil como los juegos u otras diversiones. Ello confirma la intención de la autora de autorreivindicar su yo singular frente a lo común.

Son olvidos que funcionan como un «lugar bifronte» (Pozuelo Yvancos, 2004: 181). Por un lado, afirman «la figuralidad de la construcción» (181), ya que es interesada y tergiversadora. Pero, por otro, remiten en el caso de las Memorias intimas a un texto total, "frente al que se confronta el [...] autobiográfico» (181), en que no operan aquellos descuidos.

Realmente el afán de la teoría literaria por matizar la noción de pacto autobiográfico (1994), formulada en 1875 por Lejeune como fundamento de la autobiografía, ha llevado a la superación de algunos de sus aspectos. Ese pacto de lectura, al avalar como única la identidad de autor, narrador y protagonista, sentenciaba que lo narrado alcanzaba garantías de veracidad para el lector. Sin embargo, las Memorias intimas de Juana de Vega, como perteneciente a la literatura del yo, es un texto fronterizo, en el que mantener sólo un valor estrictamente referencial sería lo mismo que negarle la ficcionalidad y, por tanto, su dimensión literaria (Pozuelo Yvancos, 1993).

Evidentemente, en la construcción de su personalidad, de su yo individual, por la propia Juana a través de la escritura de sus Memorias intimas, en ese hibridismo del género autobiográfico entre la mimesis y la poiesis (Villanueva, 1991), predomina la segunda sobre la primera. Así, la autora coruñesa, mediante la memoria plasmada en el papel, elabora esa heroína inteligente y pragmática que protagoniza una vida plena de ingredientes románticos. Su voz femenina expresa «desde una doble marginalidad, la de mujer y la de progresista» (Romero Mateo, 2000: 236) la fábrica de una identidad genérica diferente a la tradicional de hegemónica sumisión.

En cuanto a los a los Apuntes para la historia, igualmente literatura egocéntrica, es como En honor de Mina. Memorias intimas un relato analéptico. Es decir, la condesa redacta desde su presente, y en la creación de ambas obras el yo selecciona y filtra el material recordado que transforma en sendos textos literarios. Pero mientras en la autobiografía el momento de la escritura es fundamental porque desde él se recrea o autoconstruye toda una vida, en las memorias importan más los hechos ubicados en una cronología concreta, que en el caso de los Apuntes corresponden, como antes se indicó, a los años de 1841 a 1843, durante la regencia de Espartero.

Por otro lado, en aquellos, como texto memorialístico, se refieren en primera persona unos hechos que constituyen el centro de gravedad del relato, trascendiendo lo estrictamente individual, aunque no estén al margen de la personalidad de yo narrador. Éste se convierte, así, en un yo periférico que focaliza lo contado desde el punto de vista de un yo testigo. Todo lo cual se 
vislumbra en las propias palabras de la autora: «Así concluyen los apuntes de lo ocurrido en los dos años que he estado cerca de S. M. y de que he tenido conocimiento» (953).

Además, mientras en la incompleta autobiografía de Juana de Vega, a la que nos hemos referido, la amplitud y alcance (Genette, 1972: 65 y ss.) son, respectivamente, de unos veintiocho años y de más de cincuenta en los Apuntes para la historia, el primer aspecto sólo dura dos años y menos de diez meses el segundo.

Por lo que se refiere a la intencionalidad, hay escritos memorialísticos en los que un narrador testigo de los hechos persigue en su rememoración dejar a la posteridad un testimonio de un tiempo que él juzga excepcional (Artola, 1957: VI y ss.), como sucede, por caso, en Memorias de un sesentón de Mesonero Romanos. Otras veces, sin embargo, como en las memorias de Godoy, Espoz y Mina o Alcalá Galiano, ese narrador, que ha intervenido en ciertos episodios, tiene en su relato una finalidad justificativa o apologética de una determinada conducta, víctima de ciertos ataques o considerada dudosa posteriormente.

Los Apuntes para la historia de Juana de Vega están escritos para cumplir un compromiso, «una palabra empeñada» (253) con Agustín Argüelles, tutor de la princesa Isabel y la infanta Luisa Fernanda. La autora declara al final de estas memorias:

me habló repetidas veces de lo útil y necesario que sería para todos el reunir las noticias del tiempo que habíamos estado cerca de su majestad, y me hizo darle palabra de que me ocuparía en escribir lo que pudiese (254).

Es obvio, que el hombre que la había convencido, no sin esfuerzo, para desempeñar el cargo de aya de las dos niñas, seguía teniendo, al fin de su labor, igual confianza en ella que cuando se lo había propuesto.

Juana entiende que la redacción de esos Apuntes que le pide Argüelles, creyéndolos provechosos e indispensables, tiene una dimensión trascendente. Es decir, son para la historia, en cuanto que resultan dignos de recordarse. Por tanto, los sucesos que narran deben quedar en la memoria. Y, así, la escritora coruñesa se sirve de ellos, apelando a la máxima de la veracidad -«me he propuesto contar las cosas tales como han pasado» (253)-, para hacer una sentida defensa del comportamiento del tutor, Quintana, el ayo, y de ella misma.

La condesa comienza sus memorias explicando con pormenor los motivos que le llevaron a aceptar el cargo que le solicitaban Argüelles, Quintana y otros liberales amigos de su marido. Aunque, desde la humildad, esgrimía, para rechazarlo, su ausencia de cualidades para desempeñar un cometido de «gran responsabilidad y confianza» (2) y otros motivos, de nada le valieron 
estos escrúpulos. Argüelles la convenció utilizando un doble argumento al que no podía resistirse. En la última carta, previa a la aceptación, le escribe: «la memoria gloriosa del general exige de usted este sacrificio. ¡Cuántas envidiarían padecer por ella y haber merecido asociar su suerte y su nombre al suyo!» (13).

Pero al dar su consentimiento, la condesa renunciaba a la libertad, ese «don inapreciable de disponer de mí misma» (14), lo cual significaba-diceel «sacrificio de mi tranquilidad y el de mi dichosa independencia» (13). Ya en su nueva tarea, decide seguir un plan de actuación, del que nunca tuvo remordimientos: actuar con objetividad, ejecutar lo que se le había encargado y seguir lo que su espíritu le dictase. Así, afirma:

formé la resolución de obrar con tal imparcialidad y tan exenta de pasiones y de intereses de partido, que en cualquier tiempo o circunstancias, fuesen las que fuesen, pudiese dar razón de mis actos y no perdiese la serenidad de conciencia de que he gozado toda mi vida (14).

Como Juana declara, el contenido de los Apuntes, en consonancia con su naturaleza memorialística, está sometido al yo que redacta:»probable es que ignore o haya olvidado muchas circunstancias importantes y que haya explicado mal las que he escrito» (253). Y, aunque declara que «en ningún modo se me podrá acusar de haberlas tergiversado» (253), admite la subjetividad de lo narrado pues lo hace «según el juicio que, en mis escasas luces, he podido formar» (253). Por otra parte, no hay duda que la personalidad de Juana, autoconstruida en su autobiografía, se muestra continuamente en sus decisiones y actos durante los dos años en palacio.

Varios aspectos de interés se reiteran en el contenido de los Apuntes para la historia. En primer lugar, Juana de Vega presta mucha atención a la educación de las princesas, tanto en un sentido estrictamente escolar como social y moral. Presenta negativamente la que recibían en el momento en que ella se convierte en su aya. Los profesores y profesoras de primeras letras y nociones elementales, piano, canto, francés y dibujo no eran buenos profesionales. Habían accedido al cargo no por su valía sino por recomendación, incluido el partido político al que pertenecían. Dedicaban muy poco tiempo a las lecciones y el método que se aplicaba era para una edad menor que la que tenían las augustas niñas. Inapropiado, pues, ya que las clases «debían ser formales y no de juego» (28). En consecuencia, Isabel y Luisa Fernanda estaban muy atrasadas en aritmética, tenían faltas de ortografía y aversión al francés. Eran, además, indolentes y caprichosas, defectos propios de la infancia que debieran haberse corregido antes. También se comportaban mal en la mesa no teniendo buenos modales en ella. 
Sin embargo, poseían otras virtudes que la condesa se apresta a señalar. Aparte, la espléndida relación que desde el principio mantuvo con ellas, ya que las niñas la querían e, incluso, le llamaban «ayita», eran bastante dóciles, nada orgullosas, sencillas y muy afectuosas, tenían capacidad e inteligencia, e inclinación a la caridad. No es raro, por tanto, que la condesa intentase desarrollar convenientemente estas cualidades.

Se establece, en relación a Isabel y su hermana, un vasto plan de educación que atiende tanto a la metodología de la enseñanza como a la del aprendizaje en la búsqueda de una formación integral de la persona, basada en los principios del liberalismo constitucional.

Para ello fue sustituido Ventosa, personaje intrigante, por el coronel Francisco de Luján, con no pocos problemas. Se varió el método demasiado infantil de aquel por otro que implicase la responsabilidad de las princesas, de tal manera que éstas fijasen más la atención. El confesor, Heros, les daba clase de Historia sagrada y, como odiaban el francés, les mandaba traducir, lo que hacían con facilidad, pero no lograba que lo leyesen y hablasen, aunque se las estimulaba continuamente.

Juana envió a Argüelles, tutor de las dos niñas, un oficio que contenía un completo programa. En él, aparte de su contenido, sobresalen dos aspectos muy encarnados en la condesa: la humildad y el patriotismo responsable. Con respecto a la primera, el objetivo es -dice- «someter mi método a las superiores luces de vuecencia, a fin de que se sirva indicarme todo cuanto le parezca que debe variarse en él» (55). Por lo que respecta al segundo, aclara la razón de lo antes afirmado: «pues que mi único deseo es el bien de la nación y de las augustas menores» (255).

En lo que atañe a ese «método», la condesa establece, de acuerdo con Quintana, ayo y coordinador de los estudios en palacio, que los maestros apuntasen todos los días el resultado de las lecciones en una especie de cuaderno de notas. Cuando el tutor y Juana veían la falta de aplicación de las princesas les hacían reflexionar para que comprendiesen la utilidad del estudio. Y ellas, que descubrían su enfado y tristeza, aunque protestaban, luego les enviaban cartas con excusas y promesas de enmienda.

Se les recomendaba continuamente la aplicación en los estudios y se procuraba que se aficionasen a la lectura directa u oída de libros que seleccionaba Quintana. Se favorecen todas las acciones y entretenimientos que pueden contribuir al desarrollo de las facultades físicas y morales de Isabel y Luisa Fernanda. No se trataba de imponérselas, sino de que le gustasen y aceptasen de buen grado. Así practicaban equitación, iban de paseo o al teatro, siempre que Quintana hubiese visto la obra y diese su aprobación, ya que -expone 
Juana en una línea muy ilustrada- aquella debía «servir de instrucción y entretenimiento» (55).

Se les hablaba de cuestiones que tenían que ver con su educación moral, religiosa y política, empleando una forma comprensible y adaptada a su edad. Así, se utilizaban ejemplos de la Historia dignos de mención por su virtud u otros en las que ésta brillaba por su ausencia para que imitasen los primeros y evitasen los segundos. Se les recordaba los sacrificios de España por sus instituciones y su futura reina, y los derechos que por ello había adquirido de conservar su libertad e independencia. Señala el aya que las princesas, aunque por sus pocos años no se podía esperar que se les grabasen de repente y de forma indeleble estas cuestiones, estaban atentas sin disgusto y sabían contestar si se les preguntaba.

También se les exhortaba a la benevolencia con todas las clases sociales, al amor a la verdad y a la justicia - «la caridad no conocía opiniones, y [...] la reina constitucional debía dar ejemplo a su pueblo de conciliación y de olvido» (34)-, a formarse criterio juzgando por sí mismas, no por otros, las cosas, a estar agradecidas a los ciudadanos y a que cumpliesen con los deberes que les imponía la religión.

Como a las princesas les gustaba mucho repartir limosnas, la condesa lo aprovechaba como «una lección práctica de moral, que podía ser muy fecunda en buenos resultados» (34). Así, se percataban de que había mucha gente sin recursos y les hablaba de la suerte del pueblo, de sus necesidades y de sus reivindicaciones que se le solían ocultar a quien podía remediarlas.

En todo caso, Juana de Vega que está aplicando en este programa para la educación de la futura reina de España y su hermana los principios liberales que sus padres inculcaran en la suya, subraya: «como las personas encargadas ahora de su cuidado nos habíamos propuesto no tratarlas como niñas, esperábamos conseguir dejasen obrar como tales» (45).

La respuesta del tutor al oficio del aya fue de total aprobación. Además, Argüelles refleja en ella la armonía que existía entre las personas en las que recaía la formación de las princesas: Juana, Quintana, Heros y él mismo. Todos estaban conformes en los principios en que descansaba el «plan general de su educación y enseñanza» (55). Y esto es algo que interesa especialmente en relación con la apología que la condesa hace en sus memorias del esfuerzo y la entrega que en conjunto hicieron, a pesar de las dificultades, para llevar a cabo ese programa.

La oposición -absolutistas y liberales moderados-, sin embargo, les acusaba de dejadez en sus funciones. Pero el aya coruñesa es tajante: «la obligación 
que habíamos contraído con la patria era poner los medios para que aprendiesen: los pusimos» (108).

Otro tema que reiteradamente aparece en los Apuntes es el político, que se plantea en diferentes aspectos ligados a diversas situaciones. Cabe destacar, en primer lugar, la atmósfera sediciosa contra la regencia de Espartero (18401843), ya que el general tenía enemigos no sólo entre los conservadores, sino entre sus partidarios progresistas, que estaban divididos. De triunfar, como es obvio, daría al traste con la labor de tutor, ayo y aya, ya que el nombramiento de Argüelles había venido de las Cortes y de él los otros dos.

Desde casi su llegada a palacio, Juana recibe anónimos y noticias de movimientos conspiratorios en los que estaba involucrada la guardia real. Incluso, refiriéndose a ellos, achaca su enfermedad pulmonar, además de al nuevo régimen de vida que tuvo que adoptar, a «la incesante agitación de mi espíritu por la repetición de los avisos que he dicho» (250). La situación le hacía tomar medidas y vigilar constantemente como cuando el primero de octubre recibe la sospechosa visita de un amigo de su esposo y contrario al regente. Éste la insta a escribir a la reina $\mathrm{M}^{a}$. Cristina ofreciéndole su lealtad y declarándole que el cargo que ostentaba se debía a que la habían comprometido a aceptarlo. Muy recta y prudentemente la condesa, que tiene sobrada experiencia en la involucración en operaciones oscuras de gentes que equivocadamente creían en su supuesta debilidad femenina, no lo hace porque era absurdo e indecoroso ya que la reina consideraba su nombramiento ilegal.

Todo esto desembocó en la bochornosa noche del 7 de octubre de 1841 que Juana cuenta detenidamente. Argüelles y Quintana habían tenido noticia por la mañana de que se iba a intentar asaltar el palacio. Lo que se hizo a las ocho de la tarde con la intención de raptar a las niñas, empresa que contaba con la anuencia de su madre, apoyada por los liberales conservadores. Las princesas pasaron miedo, sufrieron un gran susto y corrieron un riesgo que el aya no comprende fuese autorizado por su progenitora. Tras este suceso, se extremó la vigilancia, varias camaristas fueron procesadas, el general Diego de León ajusticiado y Dulce y los alabarderos, que habían protegido el real edificio, premiados.

Dentro del ambiente político, también ocupa un lugar importante en las memorias de Juana de Vega la función difamadora y calumniosa de la prensa opositora como El Heraldo de Madrid, Postdata o el Eco del Comercio. Con frecuencia la autora se refiere a que en ella se publicaban falsedades o comentarios interesados como que Espartero no tenía buena relación con las princesas y no las trataba con respeto, hasta el asunto de que el aya vistiese de luto por su marido. Incluso, no sólo que la pérdida de éste le producía extravíos 
mentales, sino que Argüelles no tomaba medidas por compasión hacia sus padecimientos.

Cuando los infantes Francisco de Paula y Luisa Carlota consiguen regresar a España, aunque no se les permitiese afincarse definitivamente en Madrid, visitan a sus sobrinas y se produce una campaña de prensa con diferentes fines. Por un lado, se exagera cualquier incidente que tuviese que ver con ellos y, por otro, se alaba al hijo mayor de los infantes, Francisco de Asís, y se difunde que era apoyado por Espartero al aparecer en la Gaceta su nombramiento como capitán del regimiento de Húsares, cuerpo que escoltaba diariamente a Isabel.

Los periódicos contrarios a la causa de la libertad atacaban constantemente al tutor. La escritora coruñesa lamenta el silencio de los favorables a aquella, pues no desmentían las groseras calumnias e injustas ofensas, lo que les daba credibilidad. Incluso, el Eco del Comercio, que ahora defendía los intereses del infante, inserta una noticia tomada de un periódico francés sobre una supuesta correspondencia secreta entre la reina $\mathrm{M}^{\mathrm{a}}$ Cristina y su hija acerca de su matrimonio. Juana, que no cree en la existencia de esas epístolas, denuncia en su escrito a Argüelles la trascendencia de tales infundios, apelando a su propia defensa, a la de la futura reina y a la de los encargados de las princesas. La tal noticia es

una suposición infundada y calumniosa, altamente ofensiva a su majestad, cuyo carácter inocente y candoroso se quiere presentar como lleno de perfidia, y a las personas que la rodean, y muy particularmente a mí, que por mi destino son pocas las horas en que no me hallo a su lado, como capaz de faltar a lo que debo a mi patria y al nombre que tengo la gloria de llevar (131).

Realmente el aya se muestra bastante cauta en relación a la viuda de Fernando VII. Refleja en los Apuntes cómo ésta había tratado bien a su marido, al que había nombrado, tras once años de exilio, general supremo del ejército del Norte contra los carlistas. También, cómo tras su fallecimiento (1836) le había expresado que con él la causa de Isabel perdía un gran apoyo. Por ello, Juana le estaba agradecida. Sin embargo, a pesar de disculparla por haber abandonado a sus hijas responsabilizando de ello a malos consejeros, no es tan benevolente en otros aspectos. De hecho, como antes se señaló, la involucra en el suceso del 7 de octubre y en toda una red de intrigas para prometer a Isabel con sobrino, Francisco de Asís.

Por otra parte, la condesa se asombra a su llegada al palacio de que las niñas hablasen sólo esporádicamente de su madre, pues creía que, aunque los sentimientos filiales no fuesen muy vivos, a «cada paso la nombrarían y se lamentarían de su ausencia» (49). Recuerda, además, que nunca las encontró, a 
pesar de que la princesa sí lo pensaba, «afligidas con la idea de que no volviese a verlas» (49). Es más, al recibir de Juan Carrasco unos retratos litografiados de ella, sus hijas se habían limitado a darle las gracias, lo cual le disgustó por «la indiferencia que [...] habían mostrado al oír hablar de su madre» (49).

No obstante, Isabel y Luisa Fernanda le escribían y de ella recibían cartas todas las semanas. El 8 de octubre de 1841, una vez sofocada la revuelta, vuelven a hacerlo comunicándole que estaban bien. La reina, que por algún miembro de la servidumbre sabía lo que había sucedido, les respondió en el mismo tono que empleaba habitualmente, como si nada ocurriera. Juana no puede comprender como en esa epístola $\mathrm{M}^{\mathrm{a}}$. Cristina había podido «dominar los sentimientos que yo supuse debía tener en lance igual una madre» (102).

El aya, sin embargo, y a pesar de que alguna prensa acusaba al entorno de las niñas de ponerlas en contra de la reina y de tenerlas enclaustradas, declara la falsedad de esto, pues todos procuraban inculcarles el amor hacia ella.

La labor de Juana, el tutor y el ayo, como explica ésta, se veía continuamente obstaculizada, pues, por intrigas internas, que en no pocas ocasiones estaban relacionadas con cuestiones políticas. Poco después de asumir su cargo tuvo lugar el llamado motín de las damas. Varias de las de honor de la princesa presentaron su dimisión a Argüelles sin alegar razón alguna. Era una conspiración de la grandeza de España -Juana no lo era- y los absolutistas para poner trabas a la tarea de Quintana, comprometido con una educación para las reales niñas más liberal y práctica.

Tampoco el maestro Ventosa, cuya mujer era profesora de francés, ayudó nada en este aspecto, más bien fue un claro inconveniente. Aunque liberal, era un intrigante y varios episodios desagradables tuvieron que ver directamente con él. Como antes se indicó, su método educativo, en el que primaba la diversión y no el esfuerzo, fue reprobado. Con la llegada de los infantes Francisco de Paula y su esposa se habían alterado las clases de las niñas. Por ello, Juana comunica a Ventosa que éstas se aplicaban menos y su adelantamiento era menor. Él, que ya había enviado al periódico Fray Gerundio, dirigido por un amigo, un suelto malévolo y jocoso, entrega a la condesa una «Memoria» en que se alababa y defendía, relacionando el bajo rendimiento académico de las princesas con la nueva metodología que se había implantado. El tutor le pide un plan y él le presenta esa «Memoria». Ya se señaló más arriba que fue, finalmente, apartado de su cargo, aunque se resistió cuanto pudo.

Pero, además, este personaje también formaba parte de enredos palaciegos que favorecían a Francisco de Paula. Procuraba que Isabel pasease a solas con su tía y para cooperar con su intención de casarla con su hijo, Ventosa había entregado a ésta una caja de doble fondo de su propiedad con un retrato 
del joven Francisco de Asís, diciéndole en presencia de su mujer, que sería su esposo. La tal caja, por cierto, le había sido regalada al maestro por el conde de Percent, mayordomo mayor de Francisco de Paula y su mujer Luisa Carlota. Todas sus componendas las iba averiguando Juana, que con su perspicacia habitual conseguía, sin violencias, que la futura reina se las contase. El aya le explicaba que esos comportamientos eran de desacato y, ya que su matrimonio era cuestión de ella y las Cortes, ningún particular podía intervenir. También el tutor cooperaba en esto.

Además, dentro de palacio, de donde se suponía que salían las conspiraciones e intrigas, el servicio había mostrado en diferentes ocasiones su deslealtad. Aparte el motín de las damas y las sancionadas tras el 7 de octubre, una azafata le había hecho prometer a Isabel silencio ante la declaración de que sus tíos, al contrario del aya y el tutor, la querían mucho y, por ello, debía corresponderles. La hermana de una de las camaristas encausadas le había dicho que no entregase al coronel Dulce y al teniente coronel Barrientos el obsequio de unas espadas porque nada habían hecho para merecerlas, y que nombrase en su lugar a un cuñado suyo cuando obtuviese la mayoría de edad. Juana se espanta de que se pudiese comprometer así a una niña, aprovechándose de la circunstancia de sus pocos años, puesto que cuando llega el día de pronunciar la pequeña arenga dedicada a los dos ilustres militarse por su leal condición, la princesa se niega a hacerlo llorando. El misterio lo descubrió la propia Isabel a la condesa y ésta, al igual que Espartero, le hicieron reflexionar sobre el desacierto de oír consejos de personas irresponsables.

Además, la camarera mayor, marquesa de Bélgica, presenta su dimisión al tutor. El motivo, según Juana, es que se habían desbaratado, gracias a la vigilancia, los planes que urdía en coalición con Ventosa. Ellos propalaban que la princesa escribía por la noche cartas secretas y la teniente de aya seguía un diario en el que apuntaba todo lo que se hacía o sucedía, el cual iba enviando a París.

Esta situación, al igual que otras parecidas, era tan compleja que Argüelles tuvo que dar la orden de que se separaría de su cargo a toda persona que faltase a la discreción y a la prudencia entrometiéndose en oficiosidades y gestiones que no le correspondían. Juana se apresuró a pasar una circular a las azafatas y camaristas.

Las princesas, sin embargo, nunca sentían la sustitución del personal que las atendía. Y muy contentas se quedaron cuando la condesa ocupó interinamente el puesto vacante de camarera mayor. Después de que le concediesen la Grandeza de España de primera clase, aunque ella no la quería por considerarlo una recompensa, aceptó con repugnancia aquel nombramiento definitivo, 
que le suponía, para alegría de ellas, estar más tiempo con las niñas. Era un reconocimiento, en relación con el 7 de octubre, a esas cualidades que Juana de Vega descubría en su autobiografía: serenidad, consuelo y amparo para con Isabel y Luisa Fernanda, y riesgo de la vida por protegerlas.

Aunque renuncia por escrito al tutor, temiendo las infamias de los periódicos contrarios que la tacharían de ambiciosa, y el habitual silencio de los afines, éste le responde el 10 de octubre de 1842, el día del decimosegundo cumpleaños de la futura reina de España. Pero otra vez Argüelles, como antes lo había hecho para que ostentase el cargo de aya, la convence: «no podríamos responder jamás a la nación si cediésemos en nuestra obligación de cumplir con nuestros deberes por temor a la censura de nuestros detractores» (188).

Poco después, en noviembre tiene lugar el levantamiento de Barcelona provocado por el sector algodonero, que hace reaccionar a Espartero. Esa insurrección la interpreta Juana como producto de las intrigas que se habían puesto en juego para derribar al regente y afirma que se llevó a cabo «con el pretexto ostensible de procurar la República» (197-198). La condesa defiende al general y lamenta que todos los que deseaban la consolidación de un sistema representativo en España y la felicidad de la princesa Isabel, objetivos también perseguidos por el duque de la Victoria, se hallaban afligidos porque la discordia volviese al país, después de un año de los lamentables sucesos del 7 de octubre de 1841.

En 1843, Espartero se vio obligado a disolver las Cortes ante la hostilidad de las mismas, tras una extraña coalición entre moderados y progresistas, y convocar unas nuevas que también se opusieron a él. En ese momento fue cuando Narváez, enemigo personal y jefe del moderantismo, se pronunció en Torrejón de Ardoz, uniéndose a Prim y Serrano, siendo seguido el levantamiento en toda España. El regente, entonces, partió para Londres vía Cádiz.

Cuando Madrid capitula al cerco de los militares sublevados, la condesa mantiene fidelidad a sus principios del liberalismo progresista y se abstiene de aconsejar a Isabel para no comprometerla. Al salir al balcón la niña, mientras el pueblo la vitorea y da vivas a la Constitución, la tropa que le rinde honores calla. El 24 de julio de aquel 1843 Argüelles dice al aya que ha llegado el momento de dejar sus respectivos cargos, y que acababa de firmar su carta de dimisión. Lo cual gozaba de plena lógica pues el ministerio López -declara Juana- se había «reinstalado en el país por la fuerza de las bayonetas» (239), por lo que ella también tenía ya escrito su oficio de renuncia. La condesa relata la conmovedora escena de los llantos y gritos de Isabel que les pedía que no se marchasen y en especial a su ayita, a quien abrazaba desconsolada. Le preguntaba angustiada qué haría o respondería al ser preguntada sin sus 
consejos y los del tutor. También habla de su estado de ánimo abatido en el que, como en toda persona sensible, la emoción afloraba. La princesa no comprende la decisión y Juana tiene que explicarle -«mi conciencia no me lo permite» (240) - que abandona el cargo por coherencia:

mi reputación, señora, es un bien que no puedo sacrificar por ninguna consideración, y la perdería infaliblemente si, después del cambio político que ha habido, permaneciese por más tiempo en un cargo de tanta responsabilidad (240-241).

El personal de palacio- teniente de aya, azafatas, camaristas...- mostraban la misma desolación. Le pide a Isabel, aunque nunca había aceptado obsequios, que le regale el cuadro de alabarderos porque teme por su suerte, no sin antes asegurarle que los que «ahora han vencido son los mismos que atacaron el palacio la noche del 7 de octubre» (247). Les escribe sendas cartas a las dos princesas y en la mañana del 30 de julio abandona la residencia real.

Los dos años que Juana consagra a su «grave y honroso destino» (55) son relatados, como en todo escrito memorialístico y al contrario de la autobiografía, con un claro predominio de la mimesis sobre la poiesis (Villanueva, 1991). Es decir, de la fidelidad de lo contado a los hechos auténticamente sucedidos. No obstante, como texto perteneciente a la literatura del yo, los Apuntes para la historia no se libran de una determinada selección y orientación de los acontecimientos, realizadas, tal como apuntábamos más arriba, por una subjetividad que no es del todo ajena a ellos como sí lo sería un historiador.

En este sentido, es necesario atestiguar el enfoque pesimista con que la condesa se enfrentó mediante la escritura a esa estadía en palacio. Con frecuencia alude a que las tres personas en las que Espartero había depositado su confianza para la educación de las augustas niñas no disfrutaron de una vida placentera o sosegada. Tanto Argüelles como Quintana y ella misma sufrieron «amargos sinsabores» (172), fatigas, desvelos, «miserables intrigas» (168), «graves disgustos» (168), «azarosas circunstancias» (26-27) y se mantenían en «continua alarma» (48). Sin embargo la escritora gallega, que forma un auténtico equipo con el tutor y el ayo, subraya la gran responsabilidad a la que se habían entregado:

teníamos un objeto y reuníamos nuestros esfuerzos para conseguirlo, que era la felicidad de nuestra patria, con la que enlazábamos estrechamente la de aquellas dos tiernas plantas confiadas a nuestra lealtad y celo (27).

A ello se dedicaron con abnegación renunciando a todo tipo de comodidades e intereses, resistiendo en un medio asfixiante y hostil. Sólo una vez Juana parece estar dispuesta a arrojar la toalla cuando se suman a la dimisión de la camarera mayor, la expulsión y resistencia de Ventosa, el asunto del retrato de 
Francisco de Asís, síntoma evidente de que su padre quería casarlo con Isabel al margen de la Constitución, y las polémicas en los periódicos. Así, declara:

yo, aburrida ya anteriormente al ver tan descarada mala fe y cansada de luchar sin descanso contra las intrigas tan torpes y descaradamente urdidas, no solo me negué, en los primeros momentos, a admitir el desempeño de la camarería mayor, sino que signifiqué al tutor mi resolución de retirarme tan pronto como las acusaciones [de la duquesa de Bélgica] se aclarasen (166-167).

No es raro, si se piensa que Juana de Vega sufrió una gran presión interna y externa en el ejercicio de sus cargos, que los Apuntes trasmitan un «tono dolorido» (Durán, 2006: 164) y no sólo por su contenido, sino porque en el momento de la escritura su autora podía comprobar la inutilidad de tanto esfuerzo. La decepción, por tanto, es el sentimiento desde el que la condesa de Mina afronta la redacción de sus memorias.

Para finalizar, cabe resaltar que aunque las dos aportaciones de Juana de Vega al género del yo, tan ligado al egocentrismo romántico en el que se inscriben, están correctamente escritas, no podemos, sin embargo, hablar de voluntad de estilo, aunque sí, como hemos ido viendo, obedezcan a las características propias de la autobiografía y las memorias.

\section{BIBLIOGRAFÍA}

ABrams, M. H., Natural Supernaturalism: Tradition and Revolution in Romantic Literature, New York, Norton, 1970.

Alfaro Amieiro, M., «Búsqueda de una identidad autobiográfica», en J. Romera y otros (eds.), Escritura autobiográfica, Madrid, Visor, 1993, pp. 69-75.

ARtola, M., «Estudio preliminar» a Memorias de tiempo de Fernando VII, Madrid, BAE, 1957, pp. V-LXIV.

CABALLÉ, A., «Memorias y autobiografías en España (siglos XIX y XX)», La autobiografía y sus problemas teóricos. Suplementos Anthropos, 29 (1991), pp. 143-169.

DumOND, L., Ensayos sobre el individualismo, Madrid, Alianza Editorial, 1987.

Durán, J. A., Los Vega. Memorias intimas de Juana de Vega, condesa de Espoz y Mina (Coruña, 1805-1872), Madrid, Sociedad Estatal de Conmemoraciones Culturales-Fundación Juana de Vega, 2006.

GenetTe, G., Figures III, Paris, Seuil, 1972.

HEGEL, G., Introducción a la estética, Barcelona, Ediciones 62, 1990.

JAY, P., El ser y el texto. La autobiografía, del Romanticismo a la Posmodernidad, Madrid, Megazul, 1993.

Lejeune, P., El pacto autobiográfico y otros estudios, Madrid, Magazul-Endymion, 1994.

Anales, 23, 2011, pp. 259-288 
PÉREZ DE GuZMÁn y GAllo, Juan, «Prólogo» a Juana de Vega Martínez, Memorias de la Excma. Sra. Condesa de Espoz y Mina, Madrid, Imprenta de los Hijos de M. G. Hernández, 1910, pp. IX-CLXIV.

Pozuelo Yvancos, J. M ${ }^{a}$., «La frontera autobiográfica», en Poética de la ficción, Madrid, Síntesis, 1993, pp. 179-225.

— «Autobiografía: del tropo al acto de lenguaje», en C. Fernández y Ma . Á. Hermosilla (eds.), Autobiografía en España: un balance, Madrid, Visor, 2004, pp. 173-181.

Romero Mateo, Ma . Cruz, «Juana María de Vega, condesa de Espoz y Mina (1805-1872). Por amor al esposo, por amor a la patria», en I. Burdiel y M. Pérez Ledesma (coords.), Liberales, agitadores y conspiradores, Madrid, Espasa Calpe, 2000, pp. 209-238.

Vega Martínez, Juana de, Apuntes para la historia del tiempo que ocupó los destinos de aya de S. M. y A. y camarera mayor de palacio. Escritas inmediatamente después de mi renuncia (1841 a 1843), en Memorias de la Excma. Sra. Condesa de Espoz y Mina, Madrid, Imprenta de los Hijos de M. G. Hernández, 1910, pp. 1-254.

- En honor de Mina. Memorias íntimas (1820 a1836), en Memorias de la Excma. Sra. Condesa de Espoz y Mina, Madrid, Imprenta de los Hijos de M. G. Hernández, 1910, pp. 17-411.

- Memorias de la Excma. Sra. Condesa de Espoz y Mina, Madrid, Imprenta de los Hijos de M. G. Hernández, 1910.

VillanueVA, D., «Para una pragmática de la autobiografía», en El polen de ideas, Barcelona, PPU, 1991, pp. 95-114.

— «Realidad y ficción: la paradoja de la autobiografía», en J. Romera y otros (eds.), Escritura autobiográfica, Madrid, Visor, 1993, pp. 15-31.

Wellek, R., Historia de la crítica moderna (1750-1950). El Romanticismo, II, Madrid, Gredos, 1973.

— «El concepto de Romanticismo en la historia literaria»y «Revisión del Romanticismo» en Historia literaria. Problemas y conceptos, Barcelona, Laia, 1983, pp. 123-176 y 117-193, respectivamente.

Fecha de recepción: 24/03/2010

Fecha de aceptación: 07/05/2010 